\title{
The Sarbanes-Oxley Act and ist Influence Upon the Internal Context of Brazilian Companies
}

Felipe Garcia Telò<felipetelo@hotmail.com>

RicardoPinha Alonso<ripial1@gmail.com>

MARÍLIA, Brasil

\section{Abstract}

Using bibliographic, jurisprudential and comparative review methodologies, as well as the scientific deductive method, this work intends to approach the subject of compliance, specially through the corporate, accounting and legal scope, with an emphasis on the reflexes of the SarbanesOxley Act (SOX) upon Brazilian companies. It approaches the concept of compliance, as well as the history of this activity as we know it, analysing the historical context that led to the promulgation of the Sarbanes-Oxley Act, namely, the scandals of Enron Corporation and Arthur Andersen, in the early 2000s. After a thorough analysis of the Sarbanes-Oxley Act main sections, this paper sustains the need of implementing the best practices of corporate governance in publicly-held companies, instigating and ethical culture revolution, aiming to attack in a more comprehensive way corporate wrongdoings and encourage the adoption of the highest standards of compliance, accountability, disclosure and fairness. Finally, it undertakes case studies to report the process of adaptation of two Brazilian companies to SOX regulations, aiming to demonstrate the challenges of the implementation of such compliance programs.

Keywords:

Compliance. Controllership. Corporate Governance. Sarbanes-Oxley Act.

\section{Introduction}

In recent times, Brazil has been plagued by an avalanche of political and ethical scandals that have placed the issues of law enforcement and the fight against corruption on the agenda of civil society's concerns. Although Brazilians are used to corrupt practices, the systemic extension of the 
sophisticated corruption schemes investigated and dismantled by the Brazilian authorities shocked the local population, especially because these acts involved joint action with public authorities and large multinational corporations, whose top executives are currently in prison.

At this point, the indignation of the Brazilian population also resides in the lack of adequate means of controlling the financial and equity balance sheets of these companies, which would enable the identification, through accounting audits, of adulterations, fraud and illicit acts committed by their directors and executives, preventing such criminal practices from reaching such an extent.

Although these issues are only on the rise now in the Brazilian public debate, they were already extensively addressed and studied by the United Nations (UN), which has already issued reports on the global cost of corruption, and by the Organization for Economic Cooperation and Development (OECD), in which the Convention on Combating the Corruption of Foreign Public Officials in International Business Transactions (1977) was signed.

In other countries, the topic was also widely discussed, with special emphasis on the United States of America, where, since the edition of the Foreign Corrupt Practices Act (FCPA), in 1977, and, more intensely, since the promulgation of the Sarbanes-Oxley Act (SOX), in 2002, a broad legal framework on anti-corruption practices in the private sector was established, with special emphasis on accounting compliance.

The aforementioned standards have ample potential for application outside the United States of America, requiring companies from around the world to adapt their provisions, implementing the highest standards of corporate governance for the promotion of business integrity, preventing illegal practices and guarantying the market confidence in companies listed on the stock exchanges.

Therefore, given the importance and diffusion of this matter, in this paper we will address aspects related to the Sarbanes-Oxley Act, especially with regard to its influence in the internal context of Brazilian companies, the levels of implementation of such legislative requirements in the Brazilian corporate context and eventual conflicts between the Brazilian and American standards to which these companies are subject.

We will make a brief analysis of the compliance theme, seeking to define and present its modalities, among which is the legal and accounting compliance, going on to analyse the historical context of the Sarbanes-Oxley Act, as well as its main provisions and its influence in the internal context of Brazilian companies, with special emphasis on those that trade securities on the New York Stock Exchange. In this endeavour, we will 
make use of bibliographic sources and the deductive scientific method, starting from general arguments to particular arguments, connected by a logical causal relationship.

\section{Compliance}

The numerous corruption scandals that have surfaced in recent years have caused a renewed social outcry for the institutionalization of higher ethical and moral standards, causing an increase in interest in compliance programs, which seeks to guarantee ethical conducts. In fact, the fight against corruption, money laundering, terrorism and extremism is closely linked to compliance programs, which unfold, in the corporate sphere, in corporate governance and risk management, optimizing confidence of the market in the corporations that implement them.

\subsection{Definition}

Etymologically, the English noun "compliance" has its root in the verb "comply", which means to act according to an order, set of rules or request. In this way, literally, compliance can be understood as the act of obeying an order, rule or requisition. According to Bertonccelli,

the term compliance originates from the English verb to comply, which means to act according to the law, an internal instruction, a command or an ethical conduct, that is, to be in compliance is to be in compliance with the internal rules of the company, in accordance with ethical procedures and current legal rules. However, the meaning of the term compliance cannot be reduced only to its literal meaning. In other words, compliance is more than just formal rules. Its scope is much broader and must be understood in a systemic way, as an instrument for risk mitigation, preservation of ethical values and corporate sustainability, preserving business continuity and stakeholder interest. ${ }^{1}$

Therefore, the meaning of the expression goes far beyond its literal one, since the compliance activity has spread and is today an institutionalized concern at the corporate level, integrating the very concept of corporate

1 Rodrigo de Pinho Bertonccelli, 'Compliance' in André C. Carvalho, Tiago C. Alvim, Rodrigo P. Bertoccelli and Otavio Venturini, Manual de Compliance (1th ed., Forense 2019) 15. 
governance and consisting of a set of internal mechanisms whose function it is to guarantee and promote good practices, encourage the private autonomy of economic agents and promote the business ethics of all employees.

Consequently, compliance could also stand for "enforcing" or "integrity", since it consists of an activity that seeks to encourage accordance with pre-stablished standards, promoting compliance with laws, regulations, internal rules, codes, policies and avoiding the occurrence of fraud, corruption and illegal acts. According to the Compliance Programs Guide, edited by the Brazilian Administrative Council for Economic Defence (CADE, in the Portuguese abbreviation),

Compliance is a set of internal measures that makes it possible to prevent or minimize the risk of violating the laws resulting from an activity practiced by an economic agent and any of its partners or collaborators. Through compliance programs, agents reinforce their commitment to the values and objectives explained therein, primarily with accordance with legislation. This objective is quite ambitious and for this reason it requires not only the elaboration of a series of procedures, but also (and mainly) a change in the corporate culture. The compliance program will have positive results when it is able to instil in employees the importance of doing the right thing. ${ }^{2}$

Hence, compliance can be defined as an activity that seeks to establish and implement mechanisms of internal control, self-regulation, self-responsibility and self-surveillance, which encourage ethics, transparency and due diligence, and which monitor compliance with laws, rules and internal regulations of corporations, avoiding the occurrence of fraud, corruption, immorality and illicit acts or, if they have already occurred, provide the means for an immediate return to the context of normality and legality .

\subsection{Modalities}

The historical facts that have driven the growth of attention on compliance programs in Brazil in recent years, notably the corruption scandals

2 Vinicius Marques de Carvalho and Eduardo Frade Rodrigues (organizers), "Guia Programas de Compliance: Orientações sobre estruturação e benefícios da adoção dos programas de compliance concorrencial” [Compliance Programs Guide: Guidance on the structuring and adoption of concurrence compliance programs] (1th ed., CADE 2016) 9. 
that "Operation Lava Jato" has brought to light, have inevitably led the national legal community to devote special emphasis to compliance in the public sector and anti-corruption. Although anti-corruption integrity programs are undeniably important, the scope of compliance programs is not limited to public sector anti-corruption, with developments in numerous areas. In fact, according to Carvalho and Rodrigues, a compliance program will rarely cover legislation relevant to just one sector or address just one type of concern. The most common is that the programs deal simultaneously with different aspects and normative diplomas. Therefore, each economic agent must take into account their own particularities when implementing a compliance program. [...] As an example of a compliance area other than that of competition, but which can be integrated into it, it is worth mentioning the anti-corruption compliance, of Law 12.846/2013. ${ }^{3}$

The extent of compliance programs and the complexity of social and technological relationships mean that the areas in which integrity programs unfold expand far beyond mere fields of law, which is why large corporations have set up separate multidisciplinary teams whose focus is on different compliance modalities. In recent years, for instance, technological development has led to a broad development of data protection compliance, the study of which requires interdisciplinarity between Law, Economics and Information Technology (IT). This is also the case for the compliance modality regulated by the object of study in this article, namely the Sarbanes-Oxley Act, which establishes rules relating mainly to accounting and managerial compliance.

\section{The Sarbanes-Oxley Act}

The Sarbanes-Oxley Act is an American law, passed in July 2002 by the Congress of the United States of America as a response to numerous corruption scandals involving companies listed on that country's stock exchanges, whose aim was to re-establish ethics in the corporate field and reinforce confidence in the capital markets.

3 Vinicius Marques de Carvalho and Eduardo Frade Rodrigues (organizers) (n 1) 9-10. 


\subsection{Historical Context}

The historical context that preceded the publication of the Sarbanes-Oxley Act in August 2002, was set against the backdrop of a series of corporate scandals unveiled after the discovery of irregularities within the scope of Enron Corporation, a Texas electricity giant. The company, headquartered in Houston, Texas, was the first to create a nationwide piped natural gas system and, in 1989, revolutionized the energy sector market by launching Gas Bank, a program under which, at fixed prices, natural gas buyers could secure long-term supplies ${ }^{4}$.

This model, which was known as "structured finance" or "hypothetical future value accounting", was devised by Enron's then Chief Executive Officer (CEO), Jeffrey Skilling, allowing it to account and trade rights to exploit infrastructures and technologies that did not even exist ${ }^{5}$. In the end, it was this system that allowed the company to grow dramatically, to the point of becoming the largest company in the energy sector in the world, with annual revenues exceeding US $\$ 100$ billion $^{6}$, as well as the sixteenth largest company on the planet and the seventh largest company in the United States of America ${ }^{7}$.

However, the Enron quickly went bankrupt in November 2001, after accusations of accounting fraud, with a debt that exceeded thirteen billion US dollars ${ }^{8}$. The Enron case is considered by many financial analysts to be the corporate crime of the century, since it involved a complex actuarial scheme that took advantage, among other things, of gaps in the sector's regulatory framework in the United States of America.

Throughout the 1990s, Enron rapidly expanded its operations to numerous areas, such as the development of gas pipelines and power plants, an expansion that required a long gestational period and a considerable investment. By doing that, the company accumulated large debts, which should affect its credit score. However, "special arrangements" were made to keep its debts and losses off its financial statements, allowing its credit

4 Seied Beniamin Hosseini and R Mahesh, 'The Lesson from Enron Case - Moral and Managerial Responsibilities' in (2016) 8, 8 International Journal of Current Research .

5 'Enron: The Smartest Guys in the Room' (Directed by Alex Gibney Magnolia Pictures 2005).

6 Hosseini and Mahesh (n 6) 37451-37460.

7 Luciana de Almeida Araújo Santos and Sirlei Lemes, 'Desafios das empresas brasileiras na implantação da Lei Sarbanes-Oxley’ (2007) 4, 1 BASE - Revista de Administração e Contabilidade da Unisinos 37-46.

8 Santos and Lemes (n 9) 37-46. 
score not to be lowered ${ }^{9}$. This was mainly due to the use of Special Purpose Entities (SPEs), used for hiding and dumping its losses in those subsidiary companies. The responsible for this strategy was Enron's Chief Financial Officer (CFO), Andrew Fastow ${ }^{10}$.

Under the then-current rules of the United States Securities and Exchange Commission (SEC), if a holding company finances less than $97 \%$ of the initial investment in a Special Purpose Entity (SPE), it would not need to carry out consolidation on its financial statements, provided that two conditions are met, that is, that the assets are legally isolated from its transferor (in this case, Enron) and that a third independent owner makes a "substantial capital investment" of at least $3 \%$ of the total capitalization of the SPE"11.

Therefore, the solution found by Enron was to find external "investors" willing to enter into an "agreement" with them and start numerous independent SPEs. In addition, in order to allow these entities to borrow money from the market, in many cases Enron offered credit guarantees from the company itself ${ }^{12}$. The main beneficiary of this scheme was its own creator, Andrew Fastow, who was also the CEO of an investment fund called LJM Investiments, responsible for controlling most of these SPEs. In fact, Enron itself did raise money in the market for LJM and some of its main investors were the largest investment banks in the United States of America ${ }^{13}$.

The absence of adequate regulatory mechanisms has allowed Enron to co-opt financial analysts from the major North American investment banks, offering gifts, bonuses and benefits as a reward for good recommendations and using influence peddling to obtain the dismissal of those who refuse to do so ${ }^{14}$. The case was also characterized by the occurrence of the so-called regulatory capture, since Enron made significant electoral donations to both the Republican and the Democratic Party, leading to the possibility of nominate friendly candidates, especially for the Federal Energy Regulatory Commission (FERC) ${ }^{15}$. Therefore, Enron's case can be classified as "synergistic corruption", since the irregularities that happened in the company were, to some extent, known to shareholders, investors,

9 Hosseini and Mahesh (n 6) 37451-37460.

10 (n 7).

11 Hosseini and Mahesh (n 6) 37451-37460.

12 ibid.

13 (n 7).

14 ibid.

15 Hosseini and Mahesh (n 6) 37451-37460. 
brokers, directors, investment banks, analysts, accountants, lawyers, politicians and public officials, who remained silent because they profited from the situation.

The first suspicions that something abnormal was happening at Enron were only raised by journalist Bethany McLean, from Fortune Magazine, in a report entitled "Is Enron Overpriced?"16, In which the reporter raised a seemingly simple question, but that no one could manage to answer, which was "how does Enron earn its money?". Following the report, an investigation was opened by the SEC and the chief auditor of Arthur Andersen, the company responsible for accounting and financial auditing at Enron, David Duncan, ordered the destruction of more than a ton of documents that could compromise those involved ${ }^{17}$.

Arthur Andersen was the oldest actuarial company in the United Sta$\operatorname{tes}^{18}$ and one of the five largest auditing and accounting companies in the world ${ }^{19}$, with more than 85 thousand employees operating in 84 countries ${ }^{20}$. Since its founding in 1913, the company has had a reputation for providing the highest quality services. However, a shift in emphasis in the 1970s introduced a new generation of auditors who advocated for clients in exchange for consulting fees, and, in time, the company's consulting division started to generate significantly higher profits than the audit division (COLLINS, 2018). According to Denis Collins ${ }^{21}$, the combination of more complex financial statements, more aggressive accounting techniques, greater concern for customer satisfaction, greater dependence on consulting fees, and smaller cost-effective sampling techniques created many problems for auditing firms. Arthur Andersen's Houston office was billing Enron $\$ 1$ million per week for auditing and consulting services, and David Duncan, the lead auditor, had an annual performance goal of $20 \%$ increase in sales. Duncan favorably reviewed the work of Rick Causey, Enron's chief accounting officer and Duncan's former colleague at Andersen. Duncan let Enron employees intimidate Andersen auditors,

16 Bethany McLean, 'Is Enron Overpriced? It's in a bunch of complex businesses. Its financial statements are nearly impenetrable. So why is Enron trading at such a huge multiple?'(Fortune Magazine, 5 March 2001).

17 Hosseini and Mahesh (n 6).

18 (n 7).

19 Hosseini and Mahesh (n 6) 37451-37460.

20 Denis Collins, 'Arthur Andersen: American Company' in Encyplopaedia Britannica (2018).

21 ibid. 
such as locking an Andersen auditor in a room until he produced a letter supporting a $\$ 270$ million tax credit.

Thus, the bankruptcy of Enron in November 2001, which started as the centre of an unprecedented crisis, ended up becoming a mere backdrop for a series of corporate scandals in other large Arthur Andersen customers, such as World Com, AOL Time Warner, ImClone, Tyco, Adelphia, BristolMyers, Squibb and Global Crossing22. As a result of these facts, Arthur Andersen was charged and convicted of obstruction of justice, which effectively led to the closure of the company, since the SEC is prohibited to accept audits of criminal convicts. The company delivered its Certified Public Accountant license on August 31, 2002 and 85,000 employees lost their jobs. Although the conviction was later reversed by the United States Supreme Court, in theory allowing the company to resume operations, the damage to its reputation was so great that it would not be a viable business ${ }^{23}$.

As such, the Enron case was the largest of a series of cases that affected the reputation of the American financial market, forcing the United States Congress to endeavour to pass a law with bipartisan support, making corporate executives criminally responsible, closing regulations gaps that allowed accounting frauds and establishing safer rules to avoid the occurrence of future similar cases. It was against this background that, in July 2002, the United States Congress passed the Sarbanes-Oxley Act, a law whose name refers to its two main defenders, Democratic Senator Paul Sarbanes and Republican Representative Michael Oxley ${ }^{24}$.

\subsection{General Background}

The Sarbanes-Oxley Act is a United States of America law, signed on July 30, 2002 by President George W. Bush, whose structure is divided into sections. It is no exaggeration to say that SOX, as the law is also known, is a true Corporate Governance Code, especially if we consider its significant length, of 1,107 sections.

As a reflection of the historical context that predated its elaboration, the SOX has as its main goal to impose new management parameters, to stimulate the best corporate governance practices, to foresee a strict internal

22 Hosseini and Mahesh (n 6) 37451-37460.

23 ibid.

24 Fabiana Farias, 'Principais impactos da Sarbanes-Oxley Act' (2004) 4, 6 Revista ConTexto. 
control of processes, to stipulate risk management standards, to restrain manipulation of accounting reports and to compel its full disclosure. As such, SOX created a new corporate governance environment. According to Oliveira and Linhares, corporate governance is understood as the practices and relationships between shareholders, board of directors, executive officers, independent auditors and fiscal council, in order to optimize the performance of companies, facilitate access to capital and return to shareholders. ${ }^{25}$

Therefore, Sarbanes-Oxley sought to introduce a true cultural revolution at the corporate level, forcing companies to implement corporate governance policies that, due to their high cost, would hardly be implemented if this legal imposition did not exist. Among these policies, there is an emphasis on internal controls and the disclosure of financial reports, as a way to encourage corporate transparency and increase confidence in this sector $^{26}$.

SOX is considered one of the most stringent regulations in the corporate sector in the United States of America, being also applicable to all foreign companies with certificates of deposit admitted to trading on United States stock exchanges ${ }^{27}$. That is to say, SOX is applicable not only to US companies, but also to foreign companies that have bounds registered with the SEC, such as, for example, Brazilian companies that have American Depositary Receipts (ADRs) admitted to trading on the United States stock exchanges.

ADRs are an instrument created in the 1920s in the United States of America to allow the shares of foreign companies to be traded on US stock exchanges in an easy and safe way for the acquirer ${ }^{28}$. They act as a kind of receipt of shares of foreign companies, which are purchased by banks in the country where the stock was issued, which are responsible for their custody. In the United States, an investment bank issues receipts for these papers and trades them, over the counter or on stock exchanges, indivi-

25 Marcelle Colares Oliveira and Juliana Silva Linhares, “A implantação de controle interno adequado às exigências da Lei Sarbanes-Oxley em empresas brasileiras Um estudo de caso", (2007)4,2 BASE - Revista de Administração e Contabilidade da Unisinos 161.

26 Marlon Messias Peixoto de Souza and Mariana Dórea Figueiredo, 'A Lei SarbanesOxley e Sua Importância para as Companhias Abertas Brasileiras a partir do Ano de 2004' (2008) 10, 42 Revista Pensar Contábil 31-35.

27 Marcelle Colares Oliveira and Juliana Silva Linhares (n 27) 161.

28 Rita Azevedo, 'Entenda o que é ADR' Criados há 70 anos, os American Depositary Receipts permitem que investidores dos EUA coloquem recursos em empresas estrangeiras' ((2017) 4 Revista Exame,. 
dually or in bundles of shares, with values in US dollars ${ }^{29}$. In the Brazilian case, there are three levels of ADRs available, namely, levels 1, 2 and 3:

Level 1 ADR can only be sold on the non-organized over-the-counter market. In level 2 receipts, the company transforms Brazilian papers into ADRs and trades on the New York Stock Exchange. At level 3, the company makes primary issuance and negotiates shares in the secondary market. These receipts may represent preferred (non-voting) or common (voting) shares. But most of the issued papers correspond to preferred shares. Usually, only large and medium-sized companies are able to launch ADR programs in the USA, as the volume of trading is high. ${ }^{30}$

Level 1 ADRs are offered exclusively on the over-the-counter market, which is why the company is subject to few information disclosure obligations. In turn, Level 2 ADRs are traded on a stock exchange, forcing the issuing company to disclose its financial information in the manner imposed by the SEC. Finally, at Level 3, ADRs are backed by new shares, with primary issuance of stocks by the issuing company, so that they are then traded on the US stock exchanges. The prestige of Level 3 ADRs, which is practically equated with the shares of American companies, is accompanied by the requirements to which they are submitted, since they are linked to the provisions of SOX and the regulations issued by the SEC ${ }^{31}$.

This is significantly important because in Brazil, contrary to what happens in more developed economies, it is not yet common for middle class people to invest in the capital market, which ends up forcing the biggest companies in the country to resort to the United States financial market, so that their stocks are traded in that country, through ADRs, as a way of raising capital. Talking about this situation, Souza and Figueiredo teach that due to cultural, political and economic factors, the Brazilian middle class still does not trust the capital market. As the solution to this problem is neither easy nor resolvable in the short term, the foreign capital market is crucial and extremely important for the approximately 40 national companies that operate on the New York Stock Exchange. Thus, adapting to the new SOX rules has become an extremely stressful, but healthy, process for the financial health of these companies. 32

For this reason, large Brazilian companies resort to the trading of ADRs in the United States capital market, such as Ambev (ABV), Gerdau

29 Rita Azevedo (n 30).

30 Agência Estado, 'Entenda melhor os ADRS' (Estadão, 20 November 2000).

31 Rita Azevedo (n 30).

32 Marlon Messias Peixoto de Souza and Mariana Dórea Figueiredo (n 28 ) 33. 
(GGB), Petrobrás (PBR and PBR-A), Vale (VALE), Brazil Foods (BRFS), Eletrobrás (EBR), National Steel Company (SID), Embraer (ERJ), Gol (GOL), Net (NETC), Sadia (SDA), Vivo (VIV), Itaú Unibanco (ITUB) and Bradesco $(\mathrm{BBD})^{33}$. Therefore, there is a need for Brazilian companies like these to comply with the requirements of the Sarbanes-Oxley Act, so that they can continue offering shares in the US market without being subject to sanctions, fines or investigations.

\subsection{Main dispositions}

As previously stated, the Sarbanes-Oxley Act is a true code, with 1,107 sections, equivalent to articles of Brazilian law. Although the act as a whole is of fundamental importance, it is possible to identify utmost important dispositions, such as those contained in Titles I, II, III, IV, VIII and IX.

In Title I, Sections 101 to 109 establish the creation of a supervisory body for independent auditing companies, called Public Company Accounting Oversight Board (PCAOB), which operates under the Securities and Exchange Commission (SEC) and has as its main function the supervision of public company auditors. It also provides for the registration of auditors, quality control of audits and standards for assessment and inspection.

In Title II, Sections 201 to 209 deal with independent auditors, establishing standards for the provision of services not included in the scope of audit practices and imposing a rotation scheme for external auditors in company inspections subject to the Sarbanes-Oxley Act. It also addresses conflicts of interest, approval requirements for independent audits and reporting.

In Title III, Sections 301 to 308 deal with corporate responsibility, imposing the creation of Audit Committees on companies submitted to SOX. It also establishes corporate responsibility for financial statements, situations that characterize improper influence on the conduct of auditors, rules regarding the distribution of bonuses and the imposition of penalties.

Among the Sections of Title III, the number 302 is particularly relevant, especially for Brazilian companies, which determines that the CEO and the CFO must personally declare that they are responsible for disclosure controls and procedures ${ }^{34}$. Therefore, senior executives of companies that

33 Jeff Reeves, 'BRIC Investing - ADR List for Brazil, Russia, India and China' (Investor Place, 16 June 2010).

34 Oliveira and Linhares (n 27) 164. 
file financial reports with the SEC, even though foreign and small, must attest and be responsible for the thorough review of the balance sheets.

It is also in Title III that one of the most controversial provisions of the Sarbanes-Oxley Act is found, namely, Section 307, which establishes rules of professional liability for corporate lawyers. This Section obliges the lawyers to notify the Chief Legal Counsel (CLC) or the CEO when they encounter material evidence of violation of the rules of the capital markets by the company itself or its agents. If there is no adequate response to the reported evidence, the lawyer must then report it to the Independent Audit Committee or the Board of Directors. This is highly controversial because of its flagrant conflict with the duty of professional secrecy.

In Title IV, Sections 401 to 409 establish the obligation to disclose in-depth financial statements, through periodic reports. They also contain provisions on conflicts of interest, requiring broad disclosure of transactions involving the company's board of directors and large shareholders. It also deals with internal controls and the cases exempted from them, the need to create a Code of Ethics and the audit of balance sheets by financial experts, with subsequent disclosure of their reports, among other provisions.

Among the Sections of Title IV, the number 404 is particularly relevant, which also requires the Chief Executive Officer (CEO) and the Chief Financial Officer (CFO) to periodically evaluate and attest to the effectiveness of internal controls and the compliance of financial reports to SOX, SEC and PCAOB rules, under penalty of imprisonment of up to 20 years and a fine of up to US $\$ 5$ million for each untrue statement made. In addition, the company's independent auditor must issue a parallel report, attesting the effectiveness of internal controls and procedures for issuing financial reports ${ }^{35}$. Also in Title IV, Section 406 instituted the mandatory elaboration of an Ethics Code, which must be widely disclosed by the company to its employees, officers and directors.

In Title VIII, Sections 801 to 807 establish corporate and criminal liability for accounting fraud, defining crimes and establishing their respective penalties. It establishes criminal penalties for altering documents and for fraud against shareholders, as well as rules regarding statute of limitations, parameters for the imposing of penalties and plea bargains by employees of companies traded on the stock exchange that provide evidence of fraud.

In Title IX, Sections 901 to 906 stablish increased penalties for white collar crimes, applicable in the event of attempts or conspiracy to commit

35 Oliveira and Linhares (n 27) 164. 
fraud and crimes against employee pension funds. It also establishes sentencing parameters for some white-collar crimes and corporate responsibility for financial reporting.

\section{The impact of the Sarbanes Oxley Act upon Brazilian companies}

One of the most important impacts of the Sarbanes-Oxley Act is its application in jurisdictions of several other countries around the world, considering the approximately 14.000 non-American companies listed on stock exchanges in the US through ADRs ${ }^{36}$. Hence, the challenge is to reconcile the SOX with the interests and norms of other sovereign states, sometimes in open conflict with it. In the specific Brazilian case, there were initial difficulties in adapting to local rules, especially regarding the independence of the members of the Board of Directors ${ }^{37}$.

As a consequence, the SEC has made some concessions to address legitimate concerns from outside the US. Taking advantage of these concessions, the Brazilian Securities and Exchange Commission (CVM) and the Brazilian Association of Publicly-Held Companies (ABRASCA) asked the SEC for authorization for the Audit Committee to be replaced by the Fiscal Council ${ }^{38}$. Referring to the Audit Committee, Souza and Figueiredo state that, the main purpose of creating this committee is to eliminate the possibility of coexistence between the company and the independent audit; its assignment is to provide conditions so that complaints about fraud related to auditing and accounting controls can be presented without risk to the whistle-blower. Once these complaints are filed, they should be investigated by this committee with complete independence and impartiality vis-à-vis the company's management. ${ }^{39}$

Despite the SOX insistence that the Audit Committee perform advisory and recommendation functions, the SEC accepted the request of CVM and ABRASCA, considered that the performance of the Fiscal Council was considered adequate to the existing corporate balance in Brazil ${ }^{40}$. However, despite this concession, numerous Brazilian companies with papers traded on the American stock exchanges, such as Petrobras and Vale, still

\footnotetext{
36 Farias (n 26).

37 ibid.

38 ibid.

39 Souza and Figueiredo (n 28) 33.

40 Farias (n 26) 9.
} 
prefer to fully comply with the requirements of the SOX, establishing independent Audit Committees ${ }^{41}$.

In fact, the CVM recommends the creation of an Audit Committee, "composed of members of the board of directors with experience in finance and included at least one director who represents minority shareholders, who must supervise the relationship with the external auditors" 42 . In addition, as a way of adapting to the requirements of the Sarbanes-Oxley Act, a series of regulatory measures were issued by Brazilian public bodies, among which a Resolution from the Brazilian Central Bank (BACEN), which regulated, in a manner compatible with SOX, the requirement of independent audit services for financial institutions.

Another requirement of the Sarbanes-Oxley Act, unparalleled in Brazilian legislation, but easy to adapt, is the mandatory elaboration and disclosure of an Ethics Code among the company's employees, directors and board members. The majority of Brazilian companies with papers traded on US stock exchanges have this code, although more often than not in a purely pro forma manner, with little to none internal disclosure ${ }^{43}$.

After almost 18 years of the Sarbanes-Oxley Act, it can be said that most publicly traded companies in the country have already adapted, albeit partially, to its provisions, instituting internal control structures, adapting processes and implementing corporate governance practices as a way of encouraging business ethics. In addition, many of the requirements of SOX are already in effect in Brazil through local laws and CVM's Instructions. Hence, few changes will be necessary to comply with American regulations $s^{44}$.

Another aspect that deserves to be highlighted is the tendency that even companies not directly subject to SOX adapt to its standards of compliance, as a consequence of an imposition of the market itself, implemented as way of obtaining a competitive advantage. According to Almeida and Duarte Junior, there is no way back for Brazilian companies other than to follow these steps. Local investors are more interested and informed and, therefore, more careful when it comes to investing their savings in companies with no commitment to transparency, risk management and corporate governance. In other words, Brazilian companies that spontaneously decide to satisfy SOX may obtain, for example, a reduction in

41 Souza and Figueiredo (n 28) 33.

42 Oliveira and Linhares (n 27) 165.

43 Souza and Figueiredo (n 28) 31-35.

44 Oliveira and Linhares (n 27) 165. 
financing costs, a better perception of investors regarding their products, and a reduction in operational and legal losses. Even privately held companies can benefit from adhering to the best risk management practices and in line with the demands of SOX.45

Forecasts about the future aside, let us see, briefly, some case studies regarding the impacts of the Sarbanes-Oxley Act on Brazilian companies subject to it.

\subsection{Case study 1: Enel Distribution Ceara (EDC)}

Enel Distribution Ceara (EDC), is an electric power company based in Fortaleza that was privatized on April 2, 1998 through an auction held at the Rio de Janeiro Stock Exchange (BVRJ), in which it was acquired by the Endesa Group, through Investluz SA, a subsidiary of the Italian company Enel SpA, based in Rome, which has securities traded on the New York Stock Exchange ${ }^{46}$

As a consequence, EDC is subject to the provisions of SOX, such as inspections by the SEC, which is why the company has been promoting a progressive structuring to the corporate governance practices, as well as the adequacy of its structures and internal controls ${ }^{47}$. The case of EDC is paradigmatic, since the company does not have ADRs traded directly on US stock exchanges, but, as a subsidiary of a foreign company traded in America, it must comply with both SOX and SEC standards.

This restructuring aims to promote transparency and accountability, with special emphasis on the disclosure of annual reports, which have been progressively improved since its privatization. Also, with regard to internal controls, there was a significant adaptation of management practices, specially upon external audits ${ }^{48}$. According to Carioca, De Luca and Ponte, thus, since the implementation of the SOX Project, COELCE has

45 Luiz Claudio Schleder Sampaio de Almeida and Antonio Marcos Duarte Júnior, 'Desafios e soluções da Petrobras em seu projeto de atendimento à Lei Sarbanes-Oxley' (2010/2011) III, 1 RAUnP - Revista Eletrônica do Mestrado Profissional em Administração da Universidade Potiguar 37.

46 Karla Jeanny Falcão Carioca, Márcia Martins Mendes de Luca and Vera Maria Rodrigues Ponte, 'Implementação da Lei Sarbanes-Oxley e seus Impactos nos controles internos e nas práticas de governança corporativa: um estudo na Companhia Energética do Ceará - COELCE’ (2010) 6, 4 Revista Universo Contábil 50-67.

47 Oliveira and Linhares (n 27) 165.

48 Carioca, Luca and Ponte (n 48) 50-67. 
performed the analysis of all its processes, aiming at adapting to the requirements of the Law and improving its internal controls. Control activities became known and monitored, always aiming at the correct functioning and mitigation of the risks involved, as a way of enabling changes in the company's control culture, with an impact on the control environment [...]. ${ }^{49}$

So, it is possible to verify that the adequacy of EDC's internal practices to the SOX provisions is very relevant, consisting of real cultural changes in the organization and directly impacting the management practices and management of the company's internal processes.

\subsection{Case study 2: Petrobras}

Petroleo Brasileiro S.A., better known by the name Petrobras, is a publicly traded company whose largest shareholder is the Brazilian Federal Government, headquartered in the city of Rio de Janeiro. Although its credibility has been severely affected by the recent scandals unveiled by "Operation Lava Jato", Petrobras remains the largest company in Brazil and Latin America, one of the thirty largest companies in the world and one of the ten largest companies in terms of market capitalization on US stock exchanges ${ }^{50}$.

Petrobras has shares on the New York Stock Exchange, which are sold through Level 3 ADRs. As such, the company is fully subject to the provisions of SOX and the regulations issued by the SEC since 2006, the deadline for adjustments to these rules by companies based outside of America ${ }^{51}$. Due to its size and importance, it is important to analyse the process of adapting Petrobras to SOX, the main challenges faced by the company in this endeavour and the solutions adopted by it in order to meet legal requirements.

In September 2004, Petrobras began the process of adapting its internal structures to SOX, creating the Integrated Project for Internal Controls Assessment Systems (PRISMA), with an impact on all the company's operating units, including its subsidiaries and controlled companies. Initially, PRISMA was created within the Internal Audit Unit of Petrobras, being monitored by the Internal Controls Management Committee. In this first

49 Carioca, Luca and Ponte (n 48) 65.

50 Almeida and Júnior (n 47) 27-40.

51 Almeida and Duarte Júnior (n 47) 27-40. 
stage, a mapping and evaluation of the company's internal processes was carried out, with risk and control assessments ${ }^{52}$. In April 2006, PRISMA was replaced in its duties and responsibilities by the General Management of Internal Controls (GGCI), linked to the Executive Management of Corporate Finance and reporting to the CFO. The reason for this change is explained by Almeida and Duarte Junior in the following terms: it is important to mention that a common mistake made by Brazilian companies when setting up the group responsible for SOX certification was repeated at Petrobras: lack of segregation of functions between PRISMA and Internal Audit. In other words, the untying of tasks that were later allocated to the GGCI, and that could not be subordinated to Internal Audit, required that at least two distinct units be involved between proposing, evaluating and monitoring the self-assessment of controls on the one hand, and the verification of the effectiveness of the controls in practice, on the other side. Thus, the creation of the GGCI - outside the Internal Audit - solved the problem of lack of segregation of activities. ${ }^{53}$

Consequently, it is possible to verify that the fact that the SOX was a legislative novelty to which few were accustomed, especially in Brazil, caused some problems to arise in the process of initial adaptation to the requirements of the American regulations. Within this panorama, the identification and recruitment of trained internal personnel to conduct the first certification related to SOX was one of the main initial obstacles to PRISMA's activities ${ }^{54}$.

With that in mind, Petrobras hired one of the largest consultancies in the world in November 2004, Deloitte, through a bidding process. The company's expertise, which had already acted in the certification processes of companies based in the US, whose initial period of adaptation to SOX was earlier, that is, December 2014, was fundamental in this process of adaptation $^{55}$. Also, in accordance with SOX requirements, Petrobras had to contract an external audit, to certify the regularity of the work of PRISMA and Deloitte itself, and the company KPMG was chosen for this purpose, also through bidding, in December $2005^{56}$.

Petrobras had to adapt not only internal and cultural processes, but also the acquisition of compatible technological resources, consistent with structures of internal controls and information technology, thus increasing

52 ibid.

53 Almeida and Duarte Júnior (n 47) 30.

54 Almeida and Duarte Júnior (n 47) 27-40.

55 ibid.

56 ibid. 
the financial cost of adapting to SOX to levels even higher ${ }^{57}$. As is to be expected in the face of the imposition of new corporate cultural paradigms, the first reaction of all parties to SOX was its perception as a mere high-cost additional bureaucracy. Initially, this was also the case. However, in the long term, the consensus has been consolidated in the sense that SOX is a valuable resource for the management of corporate risks, helping to secure corporate longevity ${ }^{58}$.

\section{Conclusion}

Corruption is a human phenomenon with economic, legal, historical and cultural dimensions, which cannot be neglected. It is not restricted to developing countries, constituting a universal human fact, which is why there is a growing global concern about the development and implementation of effective strategies to combat the practice of illegal acts. For these reasons, compliance has grown significantly in importance at a global level, being considered fundamental in the fight against corruption, terrorism, organized crime and extremism. Basically, compliance consists of the activity that seeks to stimulate accordance with legal standards, self-surveillance, ethics, transparency and due diligence, consisting, in the private sphere, of a pilar of corporate governance.

This worldwide phenomenon, which has been stimulated by the OECD, has its roots in important regulatory acts in the US, among which the FCPA (1977) and the SOX (2002), aimed at combating acts of corruption in the public and private sectors, respectively. Mainly due to the importance of the financial and capital markets of the United States of America, US compliance standards have a wide potential for extraterritorial application, forcing public officials and economic agents from around the world to promote adjustments.

Within this panorama, Brazil, although with some delay, has come to recognize the importance of implementing compliance programs, stimulating their adoption, initially in the public sector, but with increasing importance in the corporate sector. Business managers are increasingly aware of the importance of compliance as a catalyst for corporate longevity itself.

57 ibid.

58 ibid.. 
SOX is of crucial importance in this process of disseminating corporate governance practices, since its primary objective is to re-establish ethics in the business sphere, serving to reinforce the reliability of capital markets. The Act is a true Corporate Governance Code, establishing, throughout its 1,107 Sections, strict procedures applicable to the business environment, with special emphasis on the accounting and ethical aspects.

SOX is also applicable to foreign companies, provided that they have securities registered with the SEC, what, in the case of Brazilian companies, is made possible through the negotiation of American Depositary Receipts (ADRs). That is, large Brazilian companies, listed on US stock exchanges, need to submit to SOX requirements so that they are not subject to sanctions, fines or investigations by the authorities of that country. This is the case for numerous Brazilian business conglomerates and companies that are subsidiaries of groups somehow listed on US' stock exchanges.

Thus, large Brazilian corporations, as well as thousands of companies around the world, must conform to the standards established by SOX, implementing audit policies and adapting their internal organization charts, in order to promote legal compliance, accountability, transparency and a sense of justice, in a true revolution of corporate culture. 